\title{
Influence of cutting parameters on cutting forces and surface roughness in dry turning of Al using PCD and different coated tools
}

\author{
R KUMAR, S K PATTNAIK, J K MINZ, S PADHI and S K SARANGI* \\ Department of Mechanical Engineering, Veer Surendra Sai University of Technology, \\ Burla, Sambalpur 768018, India \\ e-mail: rakesh.kist02@gmail.com; sisirakantapattnaik@yahoo.co.in; jyotikminz@gmail.com; \\ snpadhi04@gmail.com; sarojsarangi@gmail.com
}

MS received 1 August 2018; revised 29 March 2019; accepted 14 May 2019

\begin{abstract}
Aluminium (Al) is the suitable material for aerospace and automotive industries due its light weight, corrosion resistance, weldability, non-magnetic and mechanical properties. But, machining of $\mathrm{Al}$ and its alloy and finding the suitable tool is really a big challenge because of its formation of BUE (Built-up Edge) and BUL (Built-up Layer). This paper presents the influence of cutting parameters (speed, feed and depth of cut) and its effect on the cutting force and the surface finish. Five different advanced cutting tool inserts (SPUN WC, SPGN WC, PCD, WC $+\mathrm{TiN}$ and $\left.\mathrm{WC}+\mathrm{Ti}(\mathrm{C}, \mathrm{N}) \mathrm{TiN}+\mathrm{Al}_{2} \mathrm{O}_{3}\right)$ at different cutting speed $\left(\mathrm{V}_{\mathrm{c}}\right)$ ranging between $300 \mathrm{~m} / \mathrm{min}$ and $700 \mathrm{~m} / \mathrm{min}$ and feed rate (f) of $0.045,0.06,0.09$ and $0.125 \mathrm{~mm} / \mathrm{rev}$ at a depth of cut of $0.2 \mathrm{~mm}$ (constant throughout the experiment) were taken for the experiment. Tool inserts were characterized by Scanning Electron Microscopy (SEM) and Energy Dispersive X-ray (EDX) analysis. The cutting forces were measured using Kistler force dynamometer. Amongst all tools, PCD provided a better result in all aspects but surprisingly WC tool provided a better surface finish with lesser tool wear. For all cutting conditions, high speed $(670 \mathrm{~m} / \mathrm{min})$ and low feed rate $(0.045 \mathrm{~mm} / \mathrm{rev})$ were recommended.
\end{abstract}

Keywords. Dry machining; force dynamometer; surface roughness; built-up edge (BUE); tool-wear.

\section{Introduction}

With the increasing demand for lightweight greater strength material for structural work, aluminium is the best choice because of its high strength to weight ratio. Aluminium and its alloying with various elements enhance this property drastically. Thus, it is highly popular in the field of aerospace, automobile and space satellites. In fact, Aluminium alloys are considered as the material which offers the highest machinability as compared to other lightweight metals like Titanium and Magnesium alloys. Here the term machinability signifies the machining performance and may be defined for a specific application by using various criteria like,

- tool wear/life

- surface finish produced

- chip morphology

- cutting forces induced

- material removal rate (MRR)

- temperature generation

*For correspondence

Published online: 26 July 2019
Machinability reveals, how effectively or efficiently a workpiece can be machined [1,2]. In dry machining, chips are removed from the workpiece by a process of intense plastic deformation at a high strain rate with the primary and secondary shear zones that subjects the cutting edges and tool face to high temperature and pressure. Thus the surface roughness and tool wear become severe during dry machining as compared to wet machining, because of welding of chips on tool face, high friction and heat accumulation at the contact surfaces between tool and workpiece.

\section{Literature review}

The demand for the proper and better tools for machining of pure aluminium and hyper-eutectic $\mathrm{Al}-\mathrm{Si}$ alloy is increasing, because it is being extensively used in the manufacturing of internal combustion engine and aerospace parts. Considering the above point, in addition to tool life, the surface finish of the machined part is an equally important requirement. During dry machining of an aluminium alloy, the tool wear is mainly caused due to the formation of an adhesive aluminium layer and built- up 
edge [3-5]. This also greatly affects the surface finish of the machined surface. The better chemical affinity of aluminium with most of the cutting tool materials adds the problem in the formation of an adhesive layer on the tool rake face during machining (formation of BUE), deteriorating the quality of the machined surface. It was concluded that by the SEM and EDS analysis for the TiN coated tool used for a short period of time under dry turning reveals two types of adhesion effects shown by the action of different mechanisms [6].

It has been observed that chemical composition, alloying elements, structural defects and suitable tool insert significantly influence the machinability of aluminium cast alloys [7]. Thus we can improve the machinability of similar composition material using various heat treatments. This increases the hardness and reduces the chances of built-up edge (BUE) tendency during the machining completion [8]. So, for the efficient machining of aluminium, we need a few special types of cutting tools. Various carbide tools with the different surface quality for the dry turning of aluminium alloy, and they observed that the HFCVD diamond-coated tool had the lowest level of deterioration but it did not produce the best surface quality [2]. This leads the researchers, towards the development of Nanocrystal diamond (NCD) coatings, which are more resistant and causes less adhesion to the cutting surface than microcrystal coatings. In addition to this, it has been found to have similar kind of surface roughness as that of solid PCD (Polycrystalline diamond) in the machining of aluminium alloys with silicon contents of about $18 \%$ [9, 10]. In their research, the compatibility of various cutting materials in dry machining of aluminium and Al-Si alloys, and showed the chemical inertness of diamond towards aluminium and its alloys was the main reason for outperforming of an uncoated tool along with some other hard-coated tools like $\mathrm{TiC}, \mathrm{TiN}, \mathrm{TiB}_{2}, \mathrm{Al}_{2} \mathrm{O}_{3}$ and $\mathrm{AlON}$ [11]. The chip underface confirmed that the diamond-coated insert performs the best among all the tool inserts. Recently the effect of cutting speed and surface chemistry of cutting tool for the dry turning of AA6005 aluminium alloy with regard to the formation of BUE has been studied [12]. They found that the CVD diamond coating WC-inserts which is inherently free of cobalt with improved rake surface finish has enormous potential in dry machining of AA6005 aluminium alloy. While machining of soft materials like $\mathrm{Al}$ and its alloys tool wear mostly takes place due to BUE, adherent layer and diffusion (at higher cutting conditions), and similarly at higher cutting conditions tool wear involve chemical action and diffusion due to high heat generation [13]. It was observed that a workpiece with greater hardness, toughness and strength results in higher tool temperature and stresses on TiC- coated WC tools leading to severe flank wear [14]. It was observed that for machining of Al MMCs PCD tool is essential for obtaining long tool life and high surface finish at moderate cutting conditions [15].
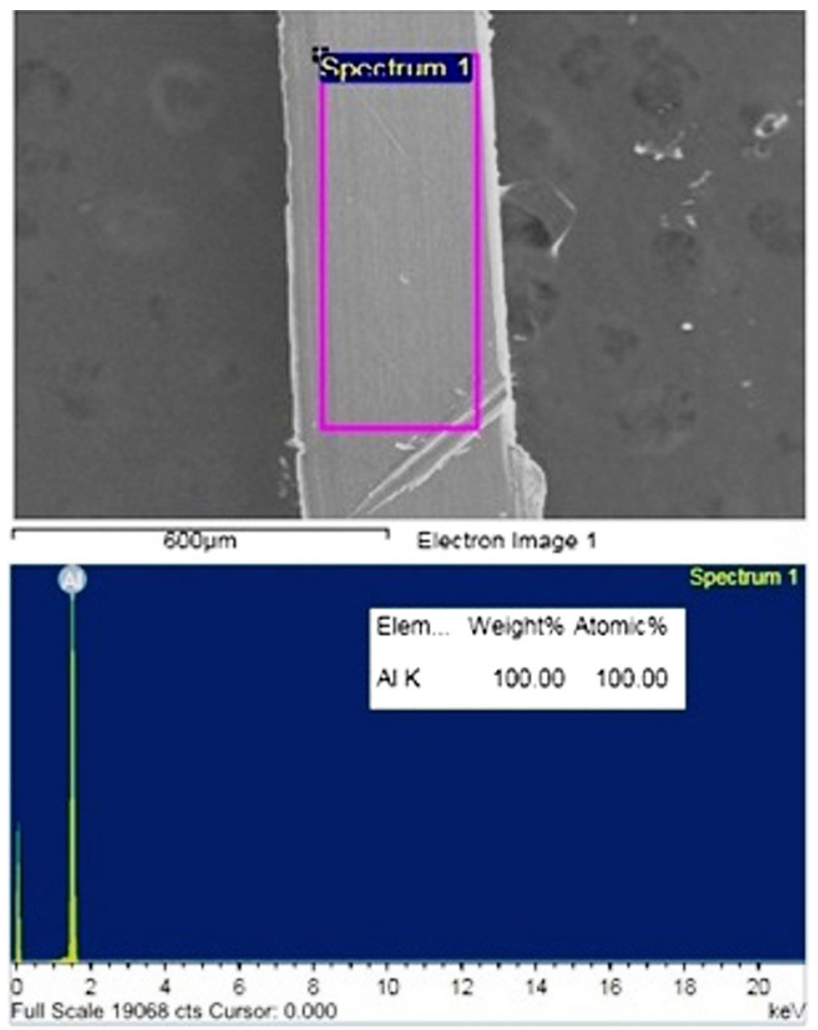

Figure 1. EDX analysis of the chip produced which shows that the workpiece is $100 \%$ aluminium.

Table 1. Description of various cutting tool and tool holders.

\begin{tabular}{lccc}
\hline Sl. & & & Tool \\
No. & Cutting tool material & Designation & Holder \\
\hline 1. & Cemented Carbide (WC) & SPUN & CSBPR \\
& (Coarse grain) & 120308 & $2525 \mathrm{M}$ \\
& & & 12 \\
2. & Cemented Carbide (WC) (Fine & SPGN & CSBPR \\
& grain) & 120308 & $2525 \mathrm{M}$ \\
& & & 12 \\
3. & Polycrystalline Diamond (PCD) & SPUN & CSBPR \\
& brazed on WC (K-10) insert & 120304 & $2525 \mathrm{M}$ \\
& & FP CD 10 & 12 \\
4. & WC + PVD TiN Coated & SNGA & CSRNR \\
& & 120408 & $2525 \mathrm{M}$ \\
& & PR 4035 & $12-4$ \\
5. & WC + CVD MT - & SNMG & CSRNR \\
& Ti(C,N) + TiN + $\mathrm{Al}_{2} \mathrm{O}_{3}$ & 120408 & $2525 \mathrm{M}$ \\
& $($ Multicoated) & PR 4235 & $12-4$ \\
\hline
\end{tabular}

The measurement of cutting forces and power consumption are becoming an important area of research in the field of machining. The force values are very sensitive to feed rate variations for the specified values of cutting speed [16]. This shows the effect of cutting feed and the depth of cut on energy partition seems to be insignificant whereas it is affected by metal cutting tribology at the high cutting 
Table 2. Working condition and different machining parameters.

\begin{tabular}{|c|c|}
\hline Cutting condition & Dry Turning \\
\hline Cutting speed & $336,426,540,670 \mathrm{~m} / \mathrm{min}$ \\
\hline Feed & $0.045,0.06,0.09,0.125 \mathrm{~mm} / \mathrm{rev}$ \\
\hline Depth of cut & $0.2 \mathrm{~mm}$ \\
\hline Run-out & $\begin{array}{c}10 \mu \mathrm{m} \text { on the headstock and } 20 \mu \mathrm{m} \text { on } \\
\text { the tailstock }\end{array}$ \\
\hline $\begin{array}{l}\text { The dimension of the } \\
\text { work-piece }\end{array}$ & $\varnothing 190 \times 460 \mathrm{~mm}$ \\
\hline
\end{tabular}

speed [17]. The objective should be, minimizing the cutting forces because when the cutting force increased it produced an adverse effect on the whole unit which includes surface finish, tool life, the durability of the machine tool, the power consumption, etc. Giasin et al [18] performed drilling operation on Al2024-T3 aerospace aluminium alloy using TiAIN coated carbide twist drill under dry condition. He inspected the surface roughness, chip formation and hole size with this he also measured the cutting force. From his investigation, he found that the cutting parameters have a significant effect on cutting force and surface quality. Different aluminium alloys (Al-7Si and $\mathrm{Al}-7 \mathrm{Si}-2.5 \mathrm{Cu}$ ) were machined Basavkumar et al [19] for their experiment. They used the lathe as the machine tool uncoated tool and polished CVD diamond coated tool inserts as the cutting tool. The machining is performed under the dry condition and from the experiment they found that the polished CVD diamond coated tool showed a better result as compared to the uncoated tool. Influence of machining parameters has been studied by Manna and Bhattacharya [20]. These researchers studied the machinability of aluminium metal matrix composite during turning with an uncoated carbide tool. The surface roughness, tools wear and BUE were

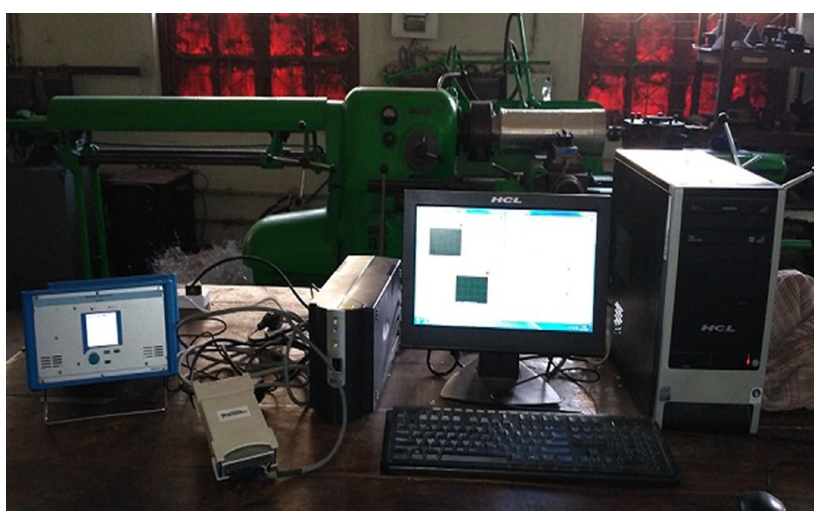

Figure 3. Experimental set-up.

analysed. They found that no BUE was formed while machining the work material at a higher speed and low depth of cut. Agustina et al [21] established an experimental analysis to study the effect of cutting parameters and nose radius on cutting forces. In their experiment they machined aluminium alloy (UNS A97075) at dry condition; design of experiment 24 was used to find out the influence of cutting parameters and tool nose radius on the cutting forces. They found that higher cutting speed leads to greater cutting forces whereas the performance of higher nose radius was better than the smaller nose radius. Davim et al [22] studied the mechanical and thermal behaviour in the machining of aluminium alloy using WC and PCD tool. They established a comparison between both the cutting tools considering various output parameters such as cutting force, temperature, shear stress and strain. They found that the PCD tool has superior performance than the WC tool, which was very much expected. Pattnaik et al [23]

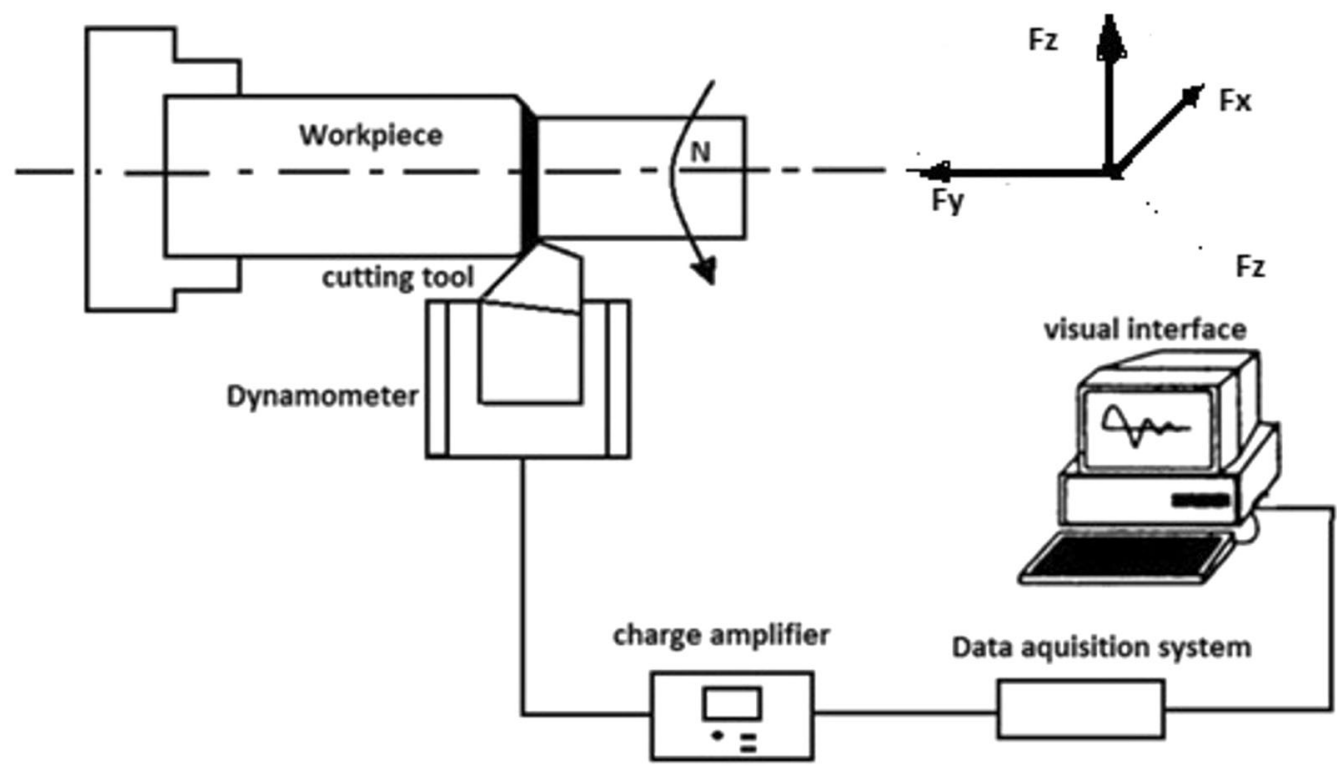

Figure 2. Schematic diagram of cutting force measurement set-up using tool force dynamometer. 

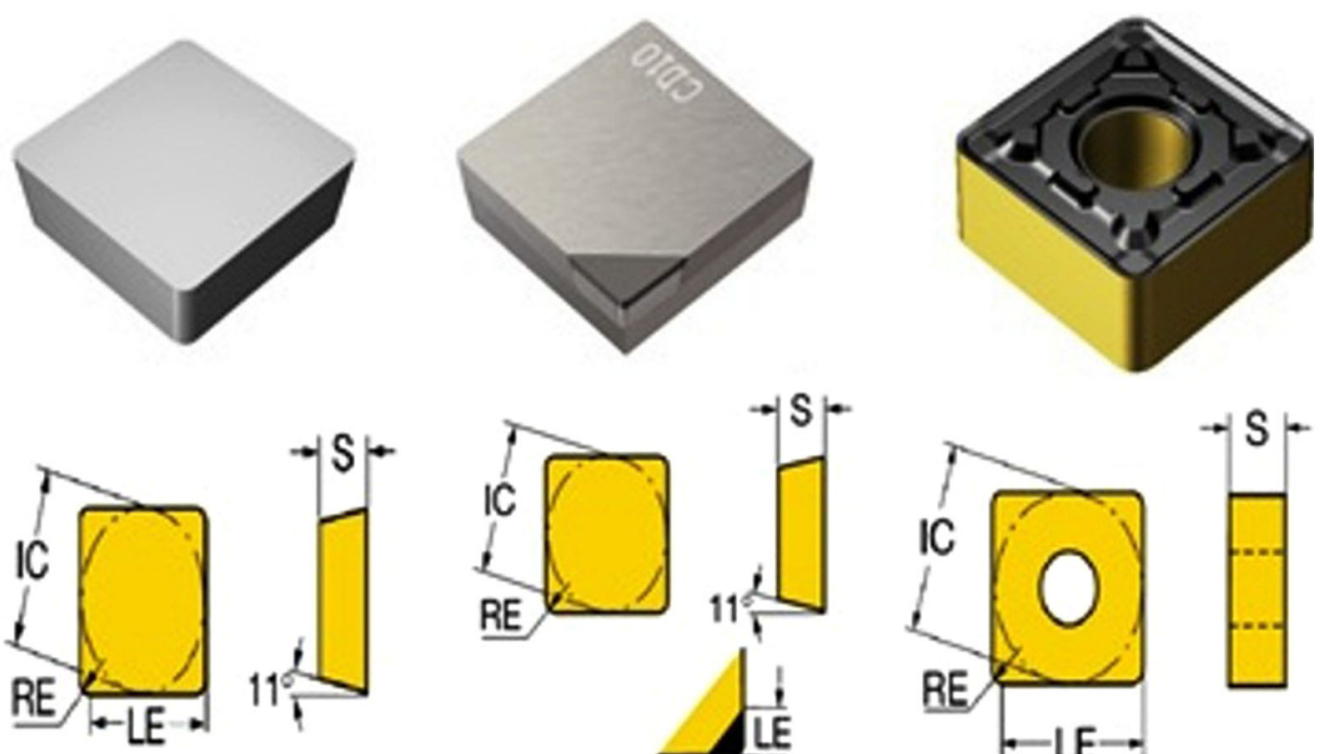

(a)

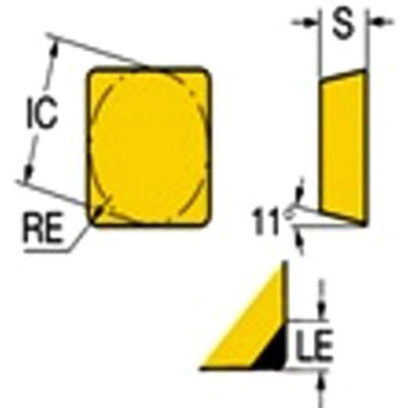

(b)
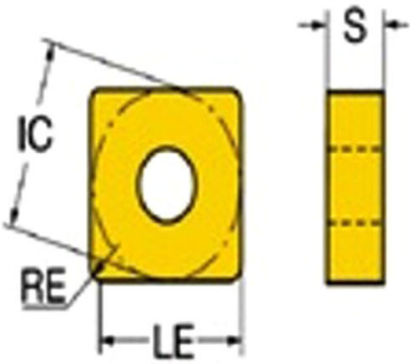

(c)

Figure 4. Tool images and its structure, (a) WC SPUN and WC SPGN insert, (b) PCD insert, (c) WC + CVD MT - Ti(C,N) + $\mathrm{TiN}+\mathrm{Al}_{2} \mathrm{O}_{3}$ (Multicoated, Source- Sandvik Coromant).

previously reported their work on dry machining of aluminium. They used five different advanced cutting tools (WC SPUN andSPGN; TiC and multicoated WC; PCD). They analysed surface roughness and tool wear and found that the PCD tool produced a better result in all aspects. Cakir et al [24] machined aluminium at different cutting parameters. They used the Minimum Quantity Liquid (MQL) method to improve machinability. They used Kennametal K313 quality CCGT 120404 HP cutting tools especially for used for machining aluminium alloys. They observed that increased cutting speed and feed rate has an adverse effect on surface finish whereas by increasing the fluid flow rate surface finish was improved.

Most of the above studies have shown various areas and good attempts were made in effective ways. However, most of them were based on wear characteristic of the various tool based on the surface finish; cutting parameters; cutting force and formation of BUE. Some used CVD coated diamond tools for machining although, CVD is a simple and effective technique for diamond coating but achieving uniform coating and good coating adhesion is a big challenge. Different advanced coated tools were also used but the effect of BUE on cutting force was not studied. Some compared only WC tool with the PCD tool, then obviously PCD tool show better performance. The use of cutting fluid may increase the machinability but it will increase the production cost also. Therefore, in view of the above, the prime goal of this work was the study of dry machining of rolled $\mathrm{Al}$ by analysing surface finish of the machined surface, chip morphology of underface, cutting force measurement and tool wear and their direct effect on cutting parameters. Another motivation for the work was to understand the effect of machining parameter for rolled aluminium to find out that if it is reasonable to machine the material under dry conditions [25-27]. This work will help to the tool design and tool manufacturing industries for their improvement, apart from that it will be very helpful in industries for selecting tools and cutting parameters for machining of aluminium according to their requirements.

\section{Experimental set-up and procedure}

\subsection{Workpiece material}

A cylindrical rolled aluminium bar has been taken as workpiece material. The dimension of the workpiece was $\varnothing 190 \times 460 \mathrm{~mm}$. The Energy Dispersive X-Ray (EDX) analysis confirms the purity of workpiece, i.e., $100 \%$ pure aluminium shown in figure 1 .

\subsection{Cutting tools and tool holders}

The machining was carried out by various tool inserts and tool holders of SANDVIK Coromant shown in table 1. All the inserts were of square shapes, but WC + PVD TiN coated and $\mathrm{WC}+\mathrm{CVD} \mathrm{Ti}(\mathrm{C}, \mathrm{N})+\mathrm{TiN}+\mathrm{Al}_{2} \mathrm{O}_{3}$ were the grooved type for the purpose of chip breaking to eliminate continuous chip. In terms of nose radius, all the tool was having a nose radius of $0.8 \mathrm{~mm}$ other than PCD tool which is having a nose radius of $0.4 \mathrm{~mm}$. 


\subsection{Machine set-up and machining parameters}

Orthogonal machining operation (Turning) is carried out on Gottwaldov Capstan lathe (semi-automatic), Type R5, precision Lathe manufactured by Gottwaldov, ZPS, Czechoslovakia having motor power of $7 \mathrm{KW}, 5 \mathrm{HP}$. All the machining parameters were listed in table 2 .

\subsection{Set-up for cutting force measurement}

A piezoelectric dynamometer (type Kistler- 9257B) was used for the measurement of change in dynamic tangential cutting force at a frequency of $1 \mathrm{kHz}$. Three cutting forces Fx (Radial Force), Fy (Feed force) and Fz (Tangential Force) were acting on the cutting tool as shown in figure 2 . The Schematic diagram in figure 2 represents the process of force measurement and the photographic image shown in figure 3. The whole set-up consists of tool force dynamometer, Kistler multi-channel charge amplifier-
5070A type and type 1687B5 cable to connect the dynamometer and charge amplifier shown in figure 2 $[28,29]$. The data obtained from dynamometer was acquired by Data-acquisition hardware NI ENET- 9163 which stores the data in the computer system using LABVIEW-2015 software. Machining was performed for 30-40 seconds for each combination of the cutting parameter.

\subsection{Surface roughness, chip underface and tool wear study}

The machined surfaces were also inspected for the surface finish produced using Taly-surf (Taylor Hobson, Surtronic S-128) with a cut-off length of $0.8 \mathrm{~mm}$ and an evaluation length of $4 \mathrm{~mm}$ for every combination of machining parameter. Chips formed in every machining condition were collected and its underface and morphologies studied using SEM.

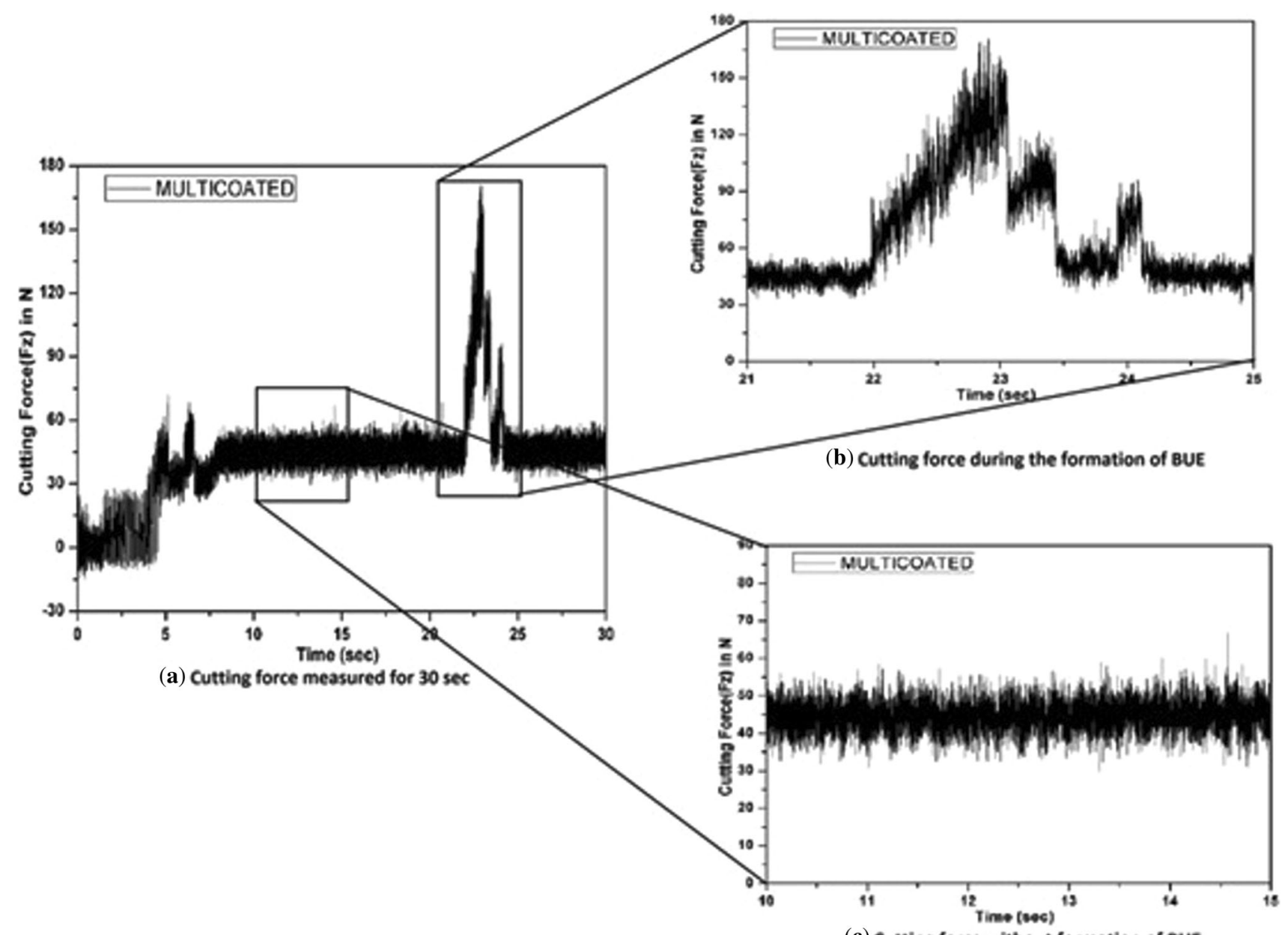

(c) Cutting force without formation of BUE

Figure 5. Graph of tangential cutting force signals obtained by Tool force Dynamometer for Multicoated tool insert: (a) graph showing the force values measured for $30 \mathrm{~s}$, (b) graph shows the enlarged part of cutting force at the time of BUE formation and (c) graph shows the Cutting force without BUE formation. 

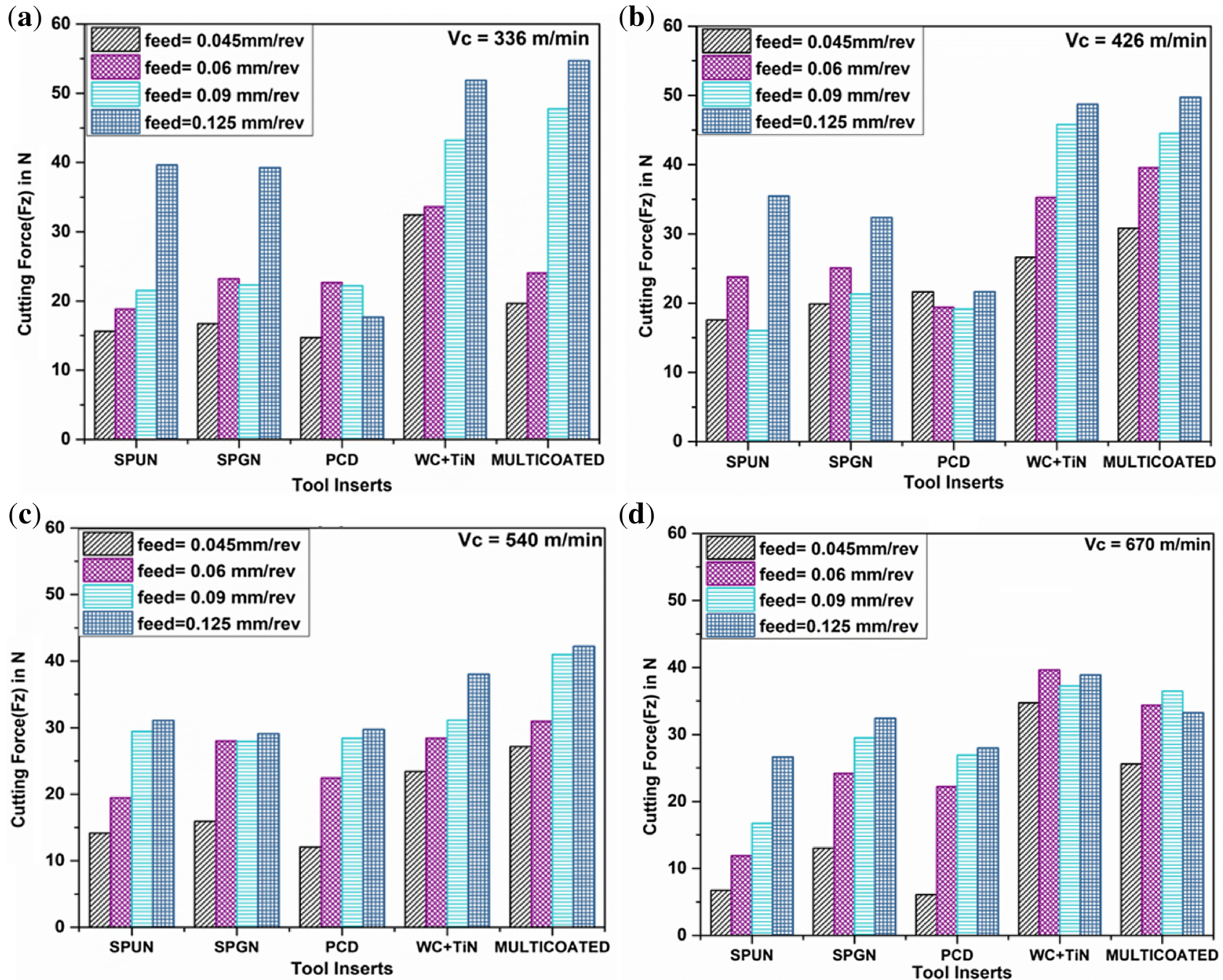

Figure 6. Graph representing the variation of cutting force with cutting velocity, (a) $336 \mathrm{~m} / \mathrm{min}$, (b) $426 \mathrm{~m} / \mathrm{min}$, (c) $540 \mathrm{~m} / \mathrm{min}$ and (d) $670 \mathrm{~m} / \mathrm{min}$

The tools were cleaned with trichloroethylene using Ultrasonic Cleaner for five minutes for each tool sample for the removal of the extra chip. Then it was dried and washed using acetone and then 2-propanol for the assessment of flank and crater wear using SEM and EDX.

\section{Results and discussion}

\subsection{Tool specification}

The tool inserts are of WC and WC substrate having brazed Diamond and some coating. Figure 4 describes the structure of the tool inserts.

\subsection{Study of cutting force}

For the measurement of cutting forces, a KISTLER-9257B dynamometer has been used. The dry turning of $\mathrm{Al}$ bar was conducted using various uncoated, coated WC insert and PCD brazed on WC insert tool. The LABVIEW-2015 software was being used for the data acquisition and interface to a computer for dynamometer. The measurement frequency of $3 \mathrm{kHz}$ with a continuous sampling mode has been selected. The cutting forces have been measured by varying the speed and feed rate for all the tools and recorded. While performing the tests it has been observed the formation of BUE with the coated tool and at the time of BUE formation, there is a drastic change in forces compared to normal force values as shown in figure 5. It has been found that the formation of BUE is very less in case of WC-SPUN and WC- SPGN tool and negligible for the PCD tool. This confirms the inertness of diamond towards aluminium $[30,31]$.

It is clear from the graph (figure 6) that with the increased feed rate the forces were increasing irrespective few cases where forces are decreasing with an increase in feed. In such cases, these errors are occurring because for the experiment only one tool insert was used from each 

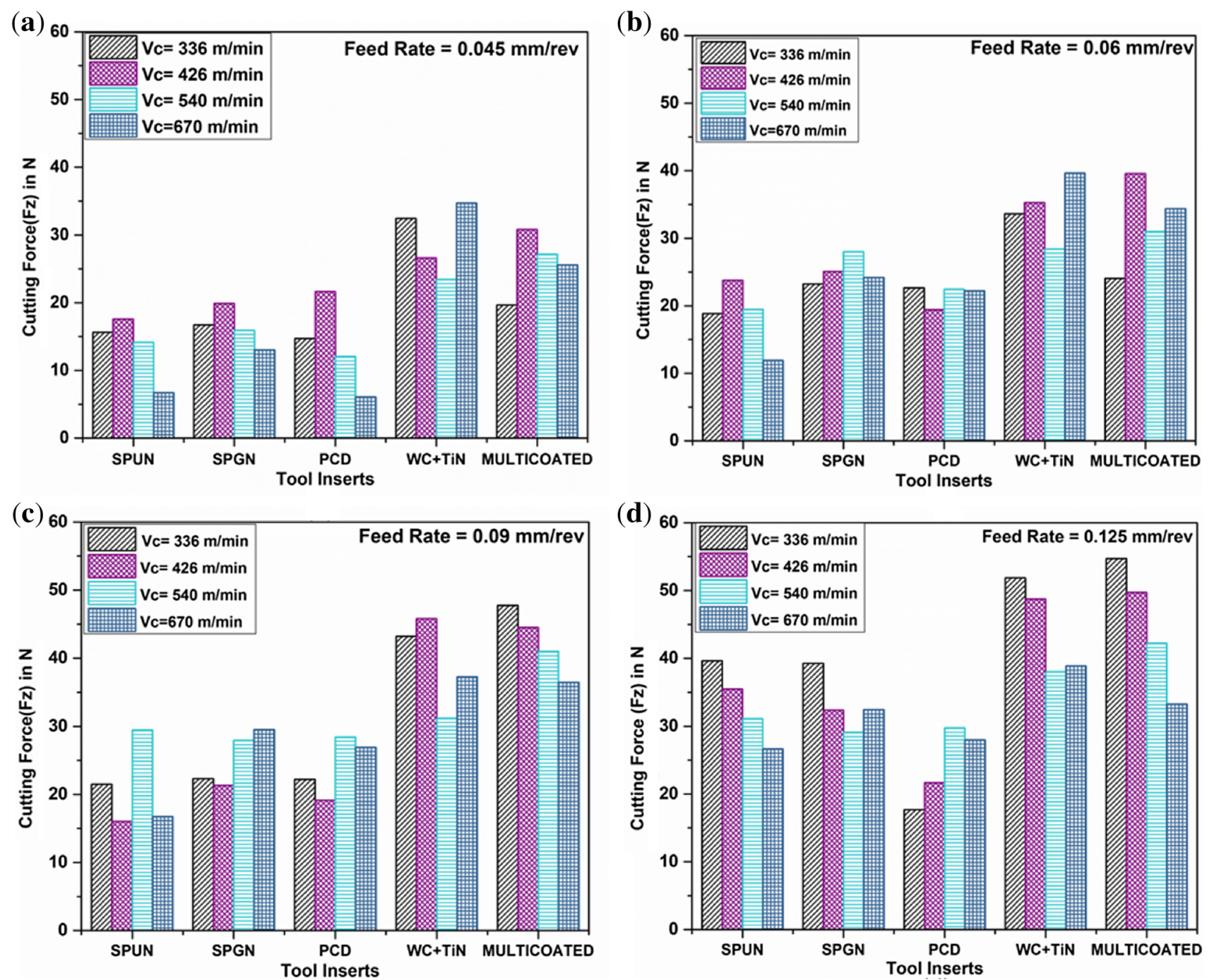

Figure 7. Graph representing the variation in cutting force with feed rate. (a) $0.045 \mathrm{~mm} / \mathrm{rev}$., (b) $0.06 \mathrm{~mm} / \mathrm{rev}$., (c) $0.09 \mathrm{~mm} / \mathrm{rev}$. and (d) $0.125 \mathrm{~mm} / \mathrm{rev}$.

category of tools and as the lathe is not fully automatic while providing the depth of cut there are chances of few errors. From the graph again we can notice that.

Figure 7 shows all the graphs for force values at a constant feed rate and varying cutting velocities, It was clearly observed from the graphs that, with the increased cutting speed the cutting force gradually decreased; which is a common phenomenon.

From figures 6 and 7 it was found that the cutting forces on PCD tool to be less than uncoated tools [32]. This was caused due to the high thermal conductivity of diamond tool which prevents the adhesion of work material to the rake face of the tool and it generally reduces the friction. Because diamond has a higher value of thermal conductivity [33, 34]. The low affinity of a diamond to the workpiece restricts the formation of BUE, whereas in case of coated tools due to greater affinity of $\mathrm{Ti}, \mathrm{TiC}, \mathrm{Al}_{2} \mathrm{O}_{3}$ and $\mathrm{TiN}$ towards aluminium the possible chances of formation of BUE. For all tools, the cutting force was minimum at low feed rate $[0.045 \mathrm{~mm} / \mathrm{rev}$.]. Again it can be observed from figure $6 a$ that, the cutting force increased when the feed rate increased. Among all cutting tool, the PCD tool produced comparatively less cutting force. But surprisingly, the PCD tool produced less cutting force at a higher feed rate $(0.125 \mathrm{~mm} / \mathrm{rev}$.) and lower speed $(336 \mathrm{~m} / \mathrm{min}$.). A similar type of results can be observed in figure 7 , at the constant speed when the feed rate increased, the cutting force was decreased. Here also, the PCD tool produced less cutting force, whereas the TiN coated tool and multicoated tool produced more cutting force; because WC SPUN, WC SPGN and PCD were having the sharper edge as compared to the coated tools. Similar kind of results was found in figure $6 \mathrm{c}$ and $\mathrm{d}$, and PCD produced better results. The cutting forces at a constant feed rate and various speed were shown in figure $7 \mathrm{a}, \mathrm{b}, \mathrm{c}$ and $\mathrm{d}$. By the overall study of the graph, it 

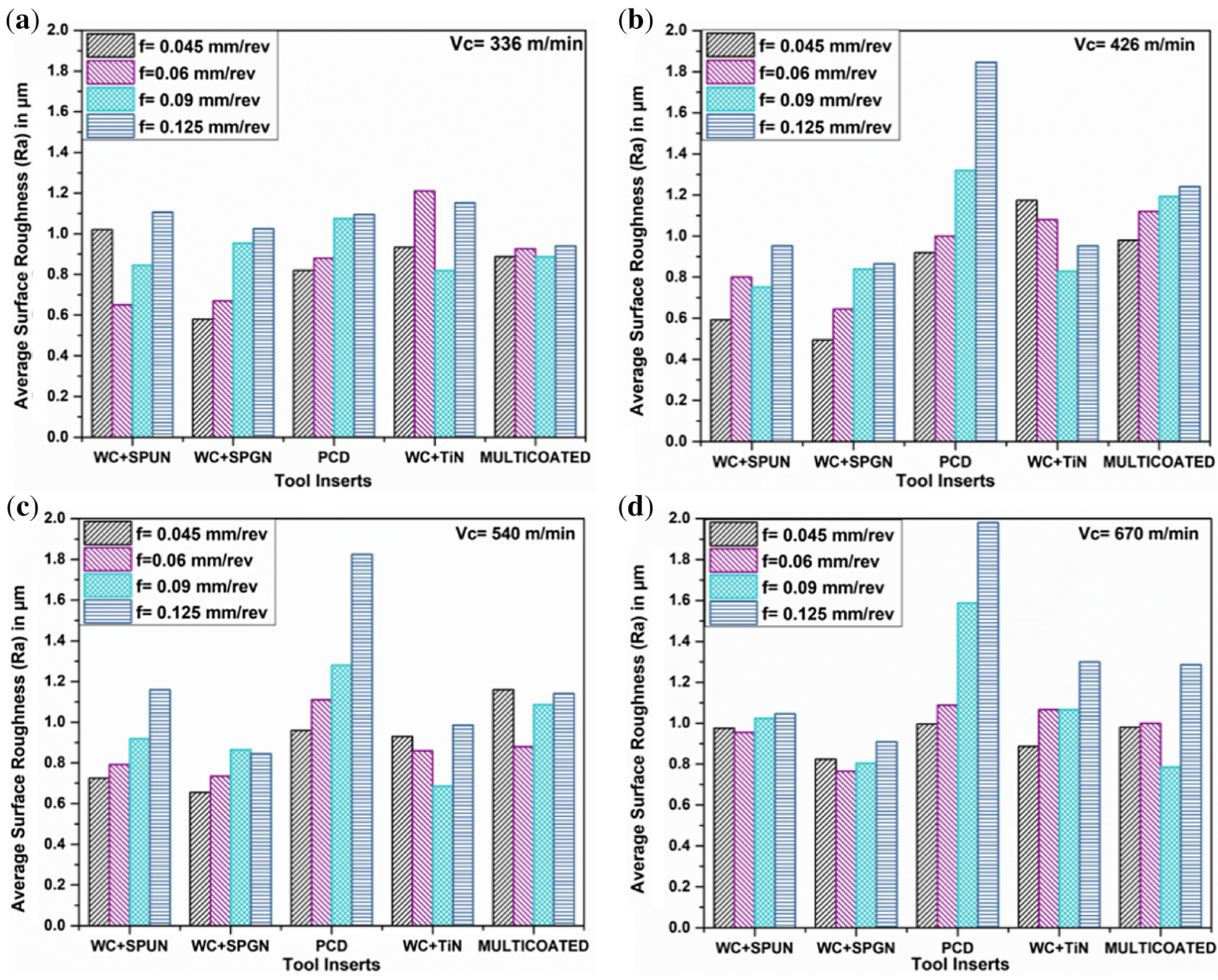

Figure 8. Graph showing average surface roughness values with velocity and varying feed rates (a) $336 \mathrm{~m} / \mathrm{min}$, (b) $426 \mathrm{~m} / \mathrm{min},(\mathbf{c}) 540$ $\mathrm{m} / \mathrm{min}$, and (d) $670 \mathrm{~m} / \mathrm{min}$.

was observed that the feed rate is directly proportional to the cutting force.

\subsection{Surface roughness study}

The surface roughness values also affect the use and cost of the product. From the subsequent graphs (figures 8 and 9), we can easily compare the surface roughness obtained using different tool inserts for the machining of pure aluminium.

Here the average surface roughness $(\mathrm{Ra})$ for all the tools has been measured after machining for each condition. The roughness was taken from three different places and their average values were considered. The WC-SPUN and WCSPGN tools the roughness values were nearly the same but the surface texture obtained was better for the SPGN tool that is because the SPGN has finer grain whereas the SPUN having coarse grain. In the case of PCD tool, we were getting the higher values only with the higher cutting velocity and feed rate but the surface texture obtained was mirror-like finish in all the conditions. This higher value obtained due to the lower value of the nose radius of the PCD tool. For the coated TiN and Multicoated tools, the roughness values are higher compared to the uncoated WC tools. The texture obtained by the coated tools was very poor when viewed which shows the adhesion of $\mathrm{Al}$ on the tool surface. But there was no adhesion or sticking of $\mathrm{Al}$ over tool surface other than the tool tip. This roughness values can also verified by comparing the chip underface stated in the later part of this work. The surface integrity considerably influenced by the sharpness and cutting nose radius of the diamond tool [35].

\subsection{Study of tool wear by SEM}

Tool wear is an important criterion for the effective machining and higher machinability of a material. In single point turning tools, the wear mainly occurs in the region of 
rake face, flank face, trailing clearance face together with a nose radius of the tool. In the case of aluminium, the main cause of tool wear was the adhesion and diffusion of $\mathrm{Al}$ with tools. As $\mathrm{Al}$ is very ductile in nature it can easily form a BUE and built-up layer (BUL) over the rake face of the tool. Tool wear is directly related to the tool life of the cutting tool. The tool which gets worn out faster is having less tool life. So it is an important parameter for the study of machinability of a material.

For the determination of tool wear there are various methods given by the researchers like loss of volume or weight, by grooving or indentation method, using microscopic images, by profilometer or surface roughness measurement, etc. [36]. Here, by the help of SEM images and EDX data, the tool wear has been inspected.

Figure 10 represents the SEM images of all the 5 tools before and after machining of Al. In the case of WC SPUN (figure 10b), the tool wear occurred on the rake surface of the cutting tool; due to the friction between the tool and chip (which produced during machining). The tool wear may occur due to the formation of BUE (WC has less inertness towards aluminium). In WC SPGN tool, a small amount of tool wear was observed (figure 10d); that is because of the fine grain of the SPGN crystal structure and higher cobalt content in it, which makes it more wear resistance. Figure 10e and $\mathrm{f}$ show the tool wear of PCD tool, a very negligible amount of tool wear was observed; as the diamond has inertness towards aluminium [37]. The tool wear result shows that the diamond tool (PCD) is the best when compared to all other tools whether it is uncoated or coated [38]. In the case of TiN coated tool (figure $10 \mathrm{~g}$ and $h$ ), it appears to be a small layer of aluminium sticking to the tip of the cutting tool. Some amount of coated part was chipped out from the nose of the cutting tool. The amount of removal of the coated part was very little because the TiN coating having good wear resistance and anti-friction properties. But for the long run, the TiN coated tool may not be suitable for machining aluminium. In case
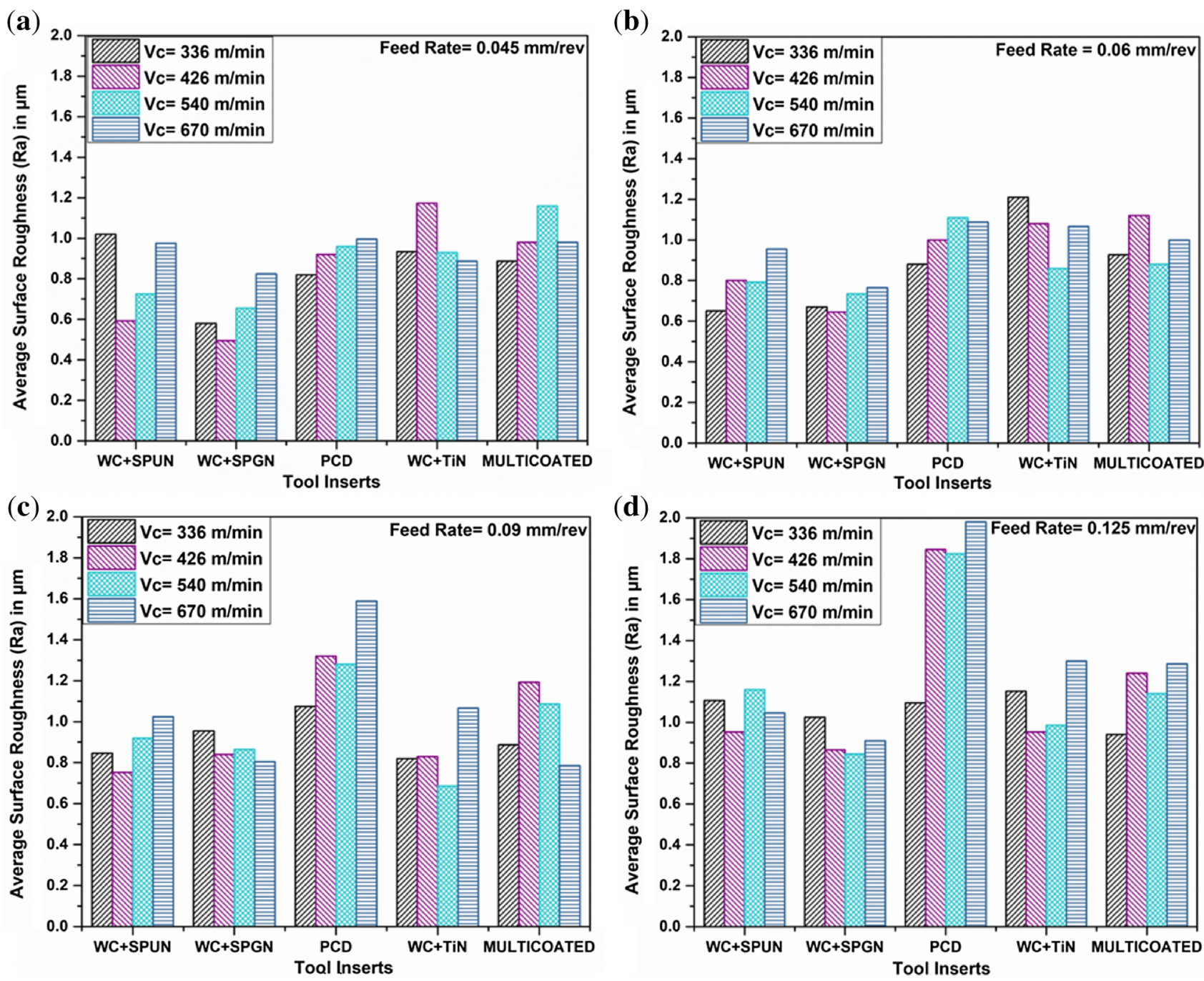

Figure 9. Graph showing average surface roughness values with constant feed rate and varying cutting velocities (a) $0.045 \mathrm{~mm} / \mathrm{rev}$, (b) $0.06 \mathrm{~mm} / \mathrm{rev}$, (c) $0.09 \mathrm{~mm} / \mathrm{rev}$ and (d) $0.125 \mathrm{~mm} / \mathrm{rev}$. 

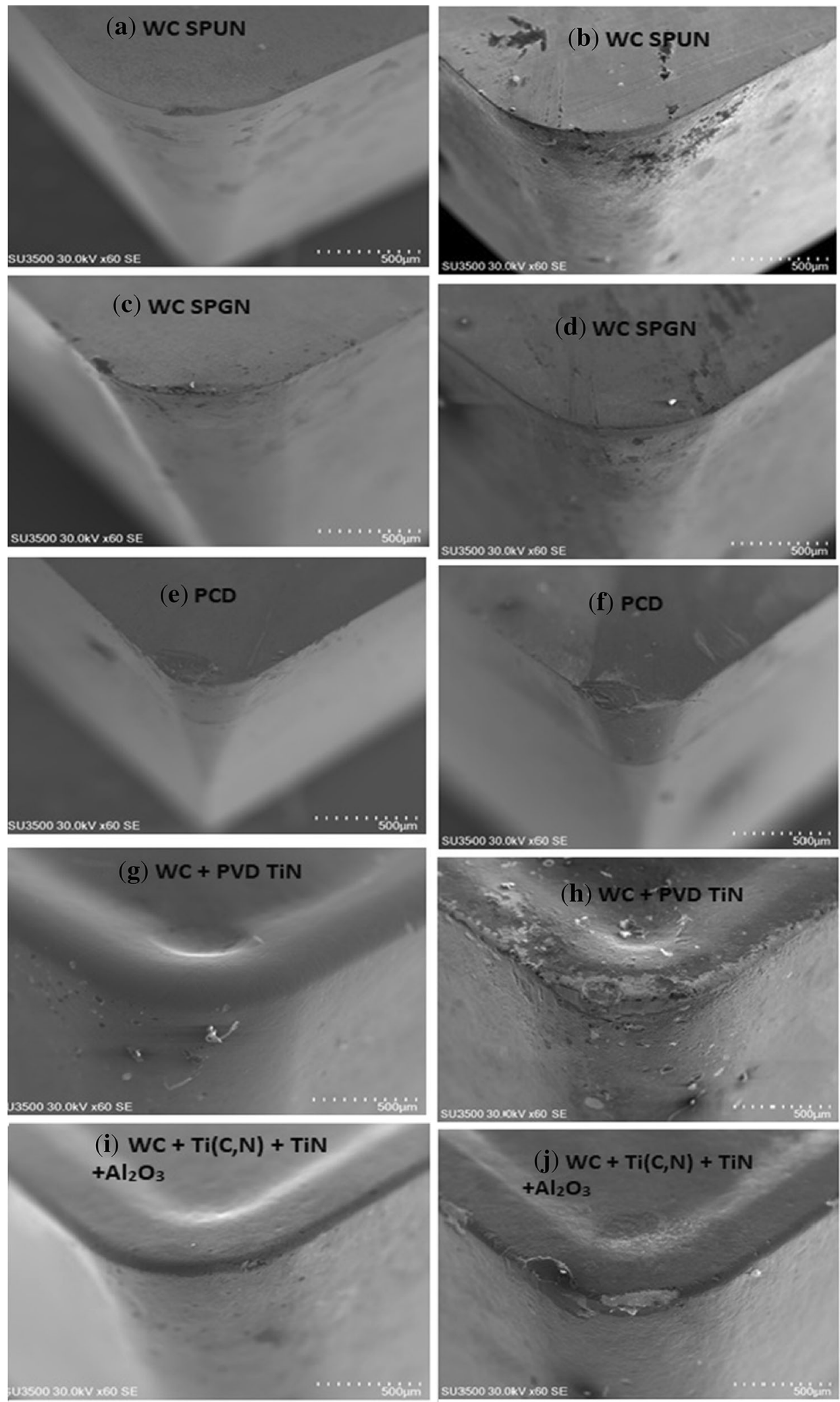

Figure 10. (A), (B), SEM images of before and after machining of WC SPUN respectively; (C), (D) SEM images of before and after machining of WC SPGN respectively; (E), (F) SEM images of before and after machining of PDC tool; (G), (H) SEM images of before and after machining of WC + PVD TiN-Coated tool, respectively; (I), (J) SEM images of before and after machining of WC + CVD $\mathrm{MT}-\mathrm{Ti}(\mathrm{C}, \mathrm{N})+\mathrm{TiN}+\mathrm{Al}_{2} \mathrm{O}_{3}$ Coated tool, respectively. 
Table 3. Representing EDX analysis of tool inserts rake faces of tool away from nose radius and at the nose radius.

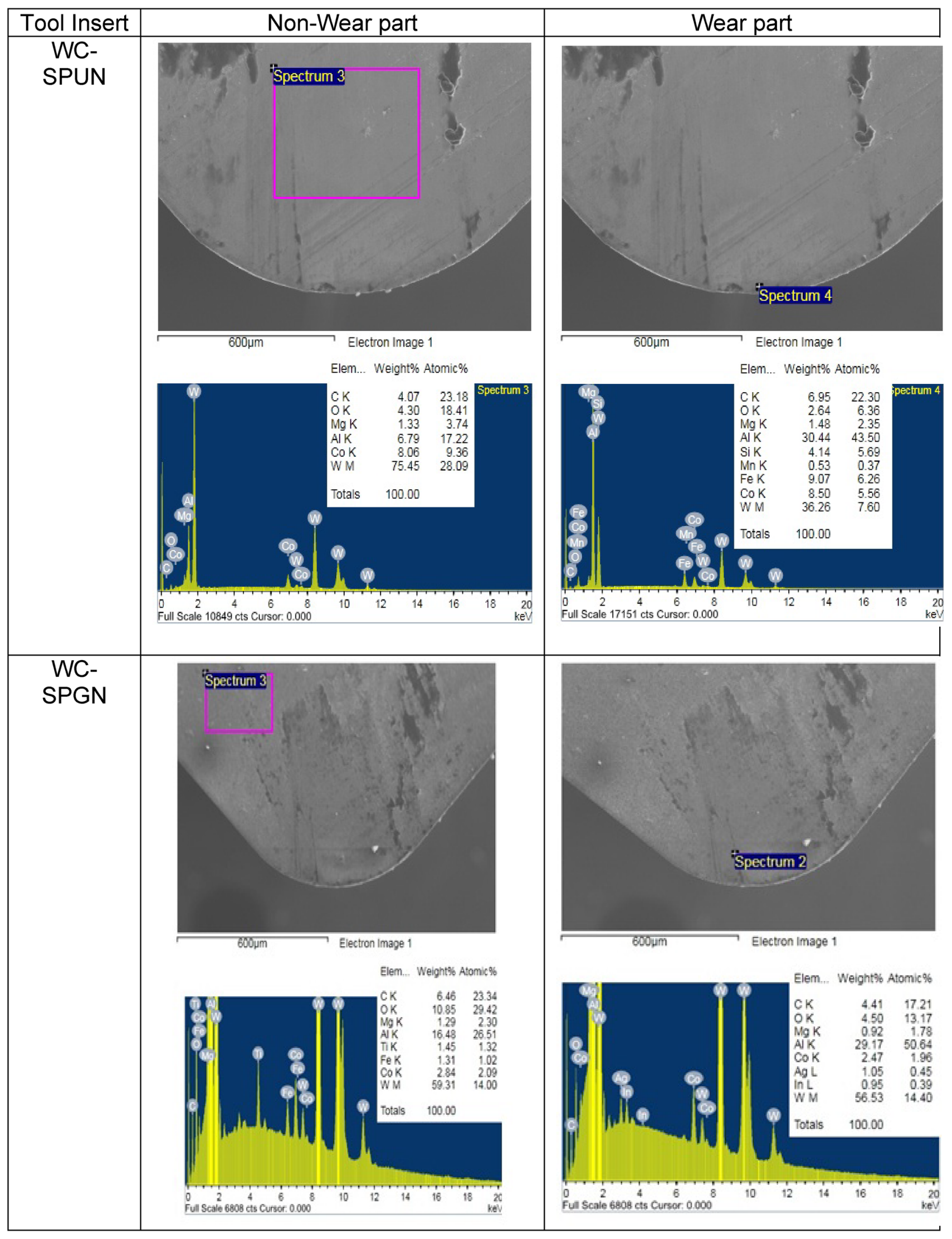


Table 3. continued

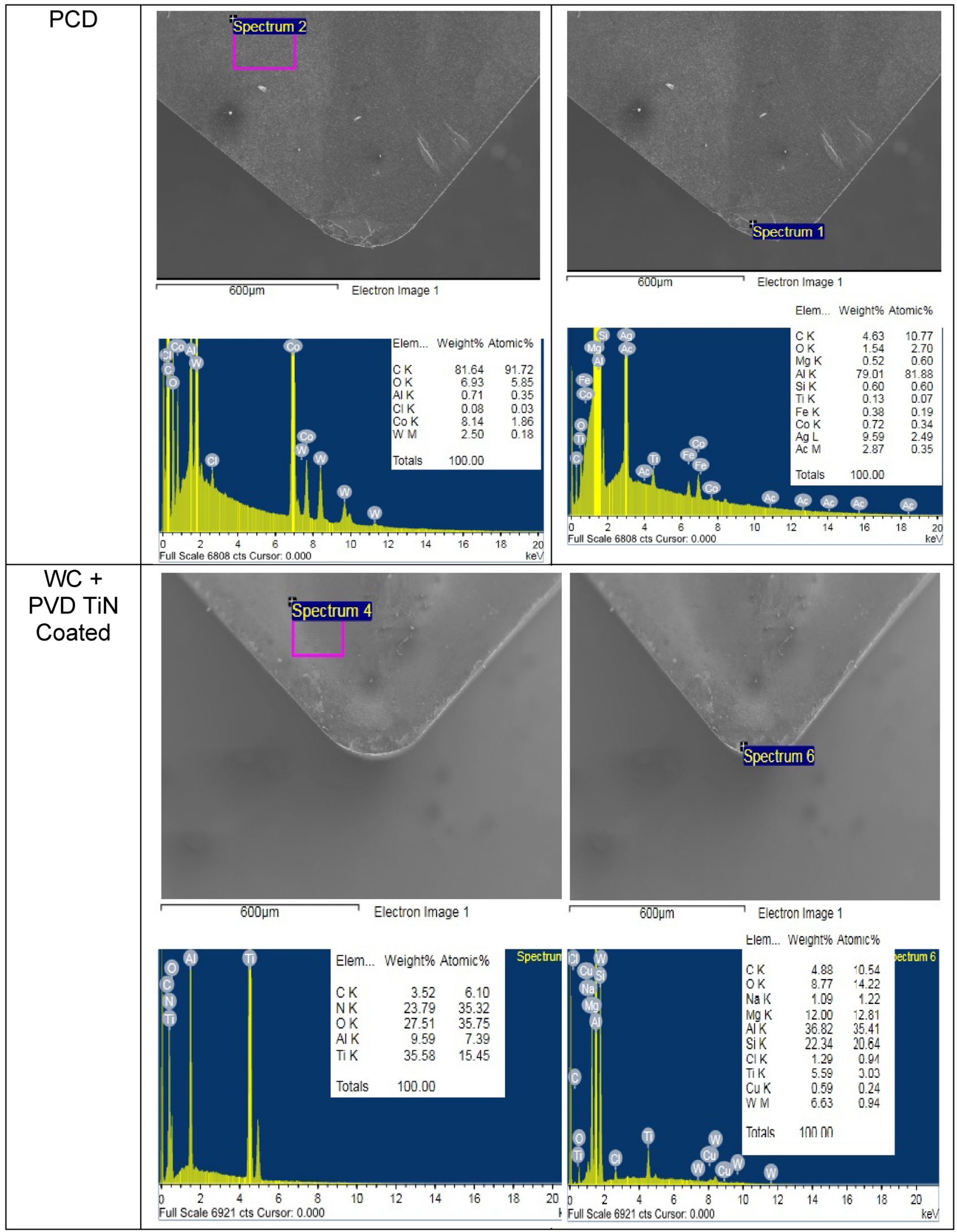


Table 3. continued

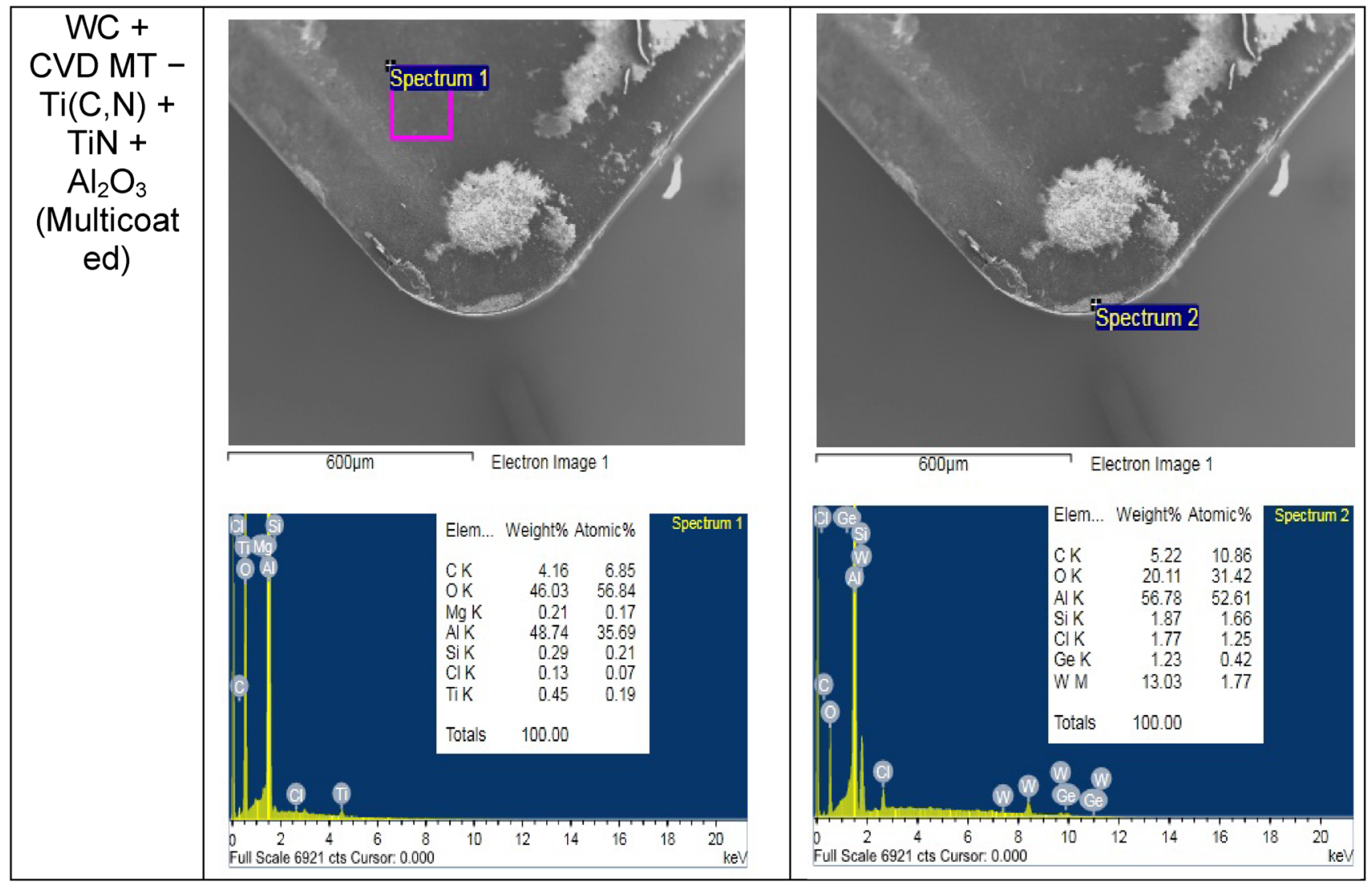

of multi-coated tool (figure 10i and j), less amount of tool wear and tool deformation was observed as compared to TiN coated tool; as it is having a triple layer coating. However, due to the friction between workpiece and cutting tool the coating at the nose of the multicoated tool was chipped away and the tool tip appeared to be somewhat blunt.

\subsection{Study of adhesiveness of $A l$}

EDS analysis is the easiest way to detect the element present over the surface. The tool rake face was studied by the EDS (Energy Dispersive Spectroscopy) at different positions. These results indicated that at the tool tip the welding of Al takes place due to high heat generation and diffusion on the cutting edge shown in table 3 . Here generally, EDS data were collected at the wear tool tip and non-wear rake face to identify the amount of weldment of different elements over it.

In the case of WC-SPUN at the tool tip, the weight percentage of $\mathrm{Al}$ is $30.44 \%$ and Amount of $\mathrm{W}$ (tungsten) is $36.26 \%$ which is very less compared to the non-wear surface. Similar kind of pattern is being shown by the WCSPGN tool. While comparing with PCD, it was observed that the weldment of $\mathrm{Al}$ at tool tip is $79.01 \%$ which is very high compared to the non-wear part of the rake face. This variation is caused due to the inertness of diamond with $\mathrm{Al}$, hence due to intense heat generation, Al sticks at the PCD tool tip [31]. For the coated tools, which got worn out more, as compared to other tools, it was observed that there is uniformity in weight percentage of $\mathrm{Al}$ on the Tool tip as well as non-wear part of the rake surface. This shows the adhesive nature of $\mathrm{Al}$ with the coating layers of the tool inserts. As the TiN coated tool got worn out more, hence in this tool the substrate WC appears more at the tool tip than other surface. For the Multicoated tool, the coating of the tool tip worn out and thus the substrate is clearly visible with $13.03 \%$ of $\mathrm{W}$ element.

\subsection{Chip under-face and chip morphology study}

The chip underface and morphologies were studied using SEM analysis. These images helped us in determining whether chips were formed by shearing or ploughing. The chips were collected for each and every machining condition. The cut chips were having two surfaces, the first one is a chip interface, which looks silver shiny and second one is the sheared surface which appears to be white in colour. The silver surface was inspected for the chip interface and compared with the surface roughness data. Table 4 
Table 4. Representing the SEM images chip-underface at different parameters.

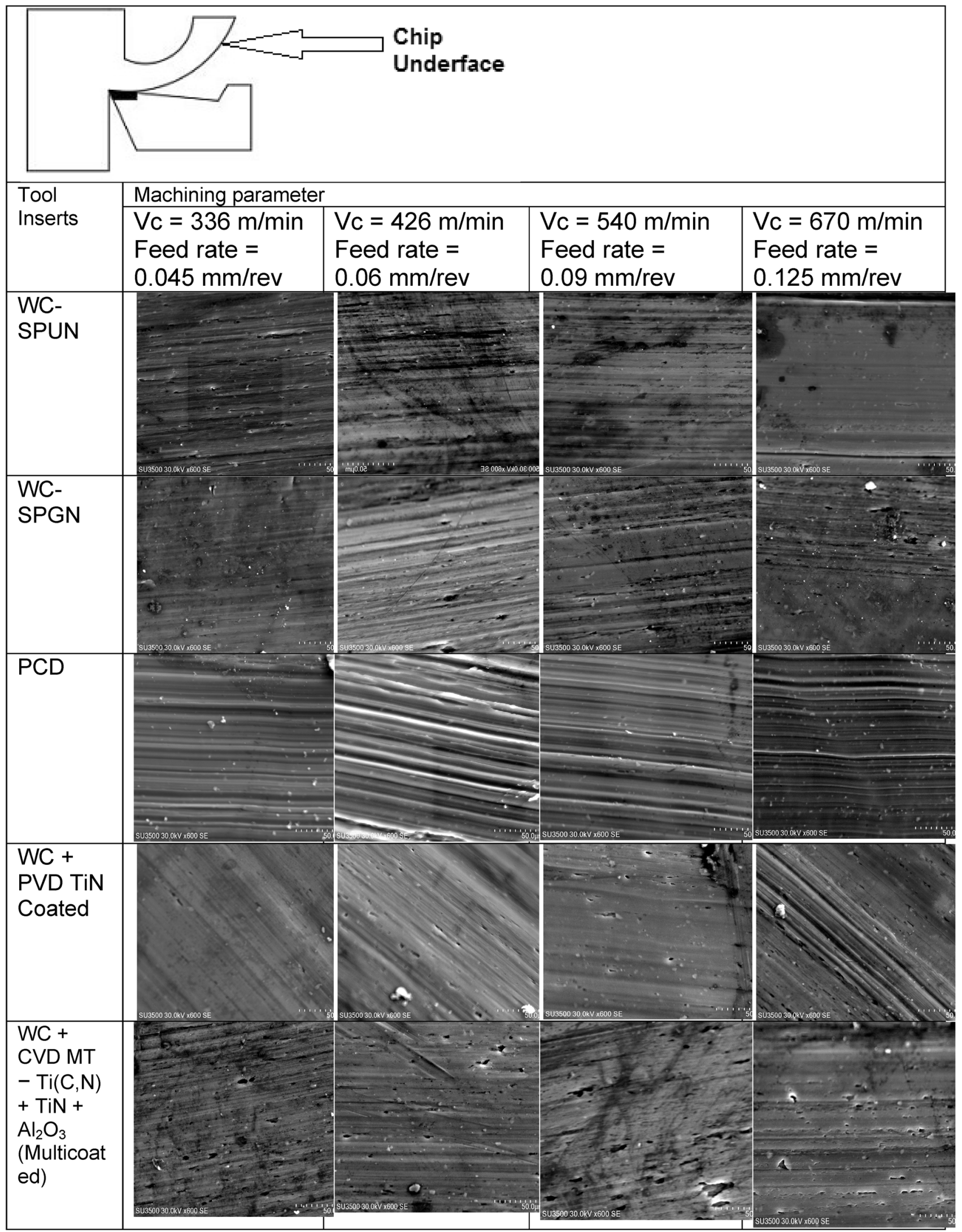



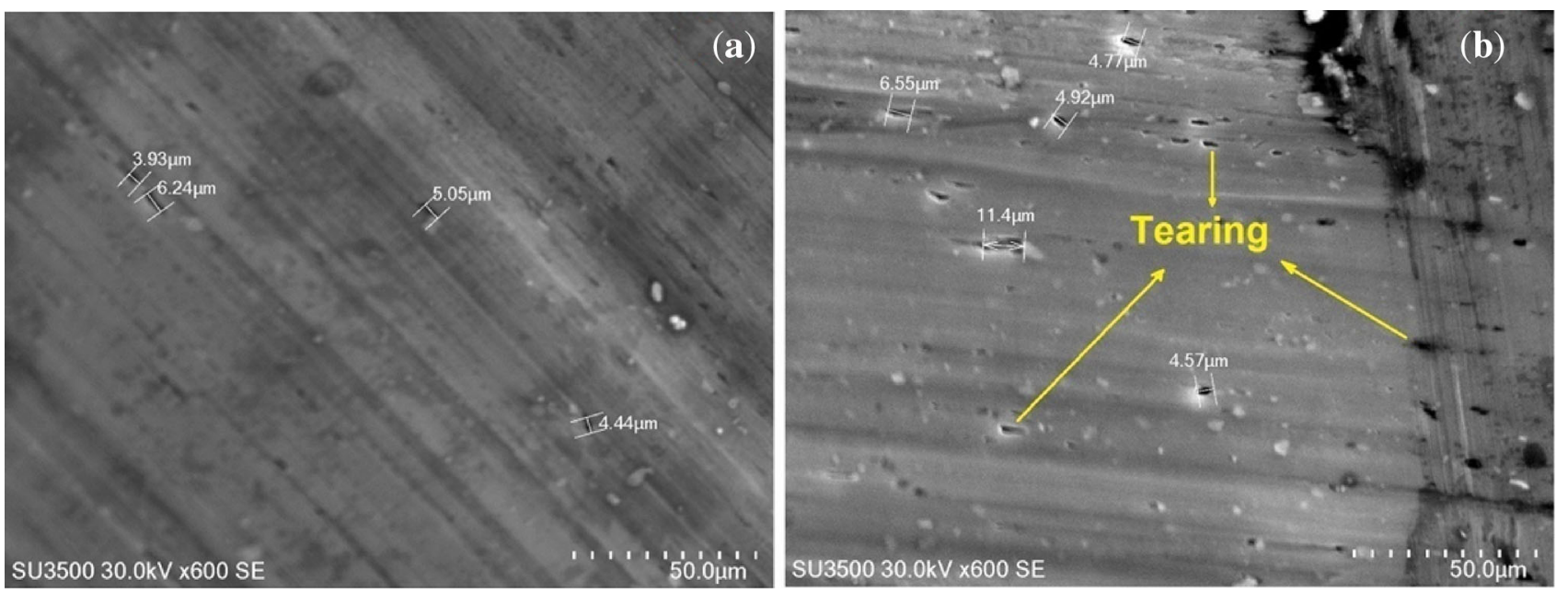

Figure 11. SEM images of chip underface showing the variation in ductile tearing at different velocity in case of machining with TiN coated tool, (a) at $\mathrm{Vc}=336 \mathrm{~m} / \mathrm{min}$ and $(\mathbf{b}) \mathrm{Vc}=540 \mathrm{~m} / \mathrm{min}$.

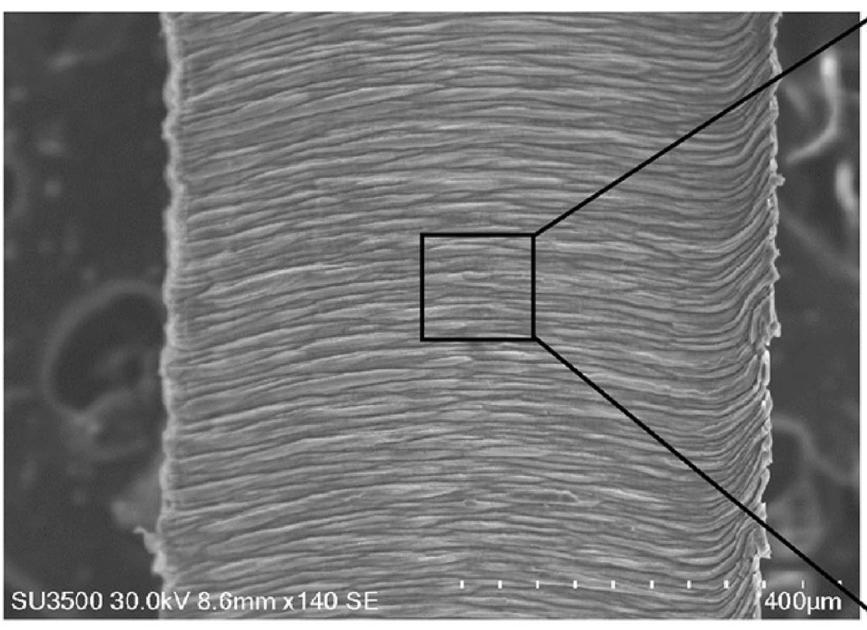

(a)

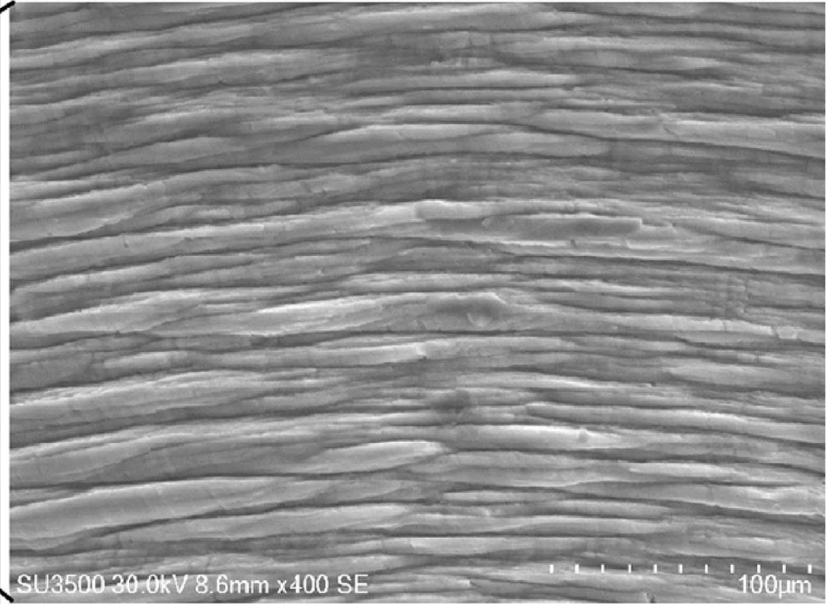

(b)

Figure 12. SEM images showing the shear band formation is very close and dense.

represents the morphology of chip underface at different machining conditions with different tools.

In the case of uncoated WC-SPUN and WC-SPGN, the chip underface were observed to be smooth and have less number of sliding marks with wide spacing. In case of SPUN with increasing feed and speed the sliding marks went on decreasing. For SPGN, the sliding marks also decrease with increasing parameters but some voids appear on the surface. A better underface was produced than WCSPUN as it has a finer grain. While machining with PCD the sliding marks are very close and uniform in regard of variation in speed and feed values. This closeness of marks is due to the lesser nose radius of the PCD tool insert. From the SEM images (figure 11) of chip underface, it was observed that the chips go under severe plastic deformation, which causes ductile tearing and this goes on increasing with increasing velocity [39]. The uniform surface profile obtained during turning by shear mode of cutting with PCD.

In case of $\mathrm{WC}+\mathrm{TiN}$ tool insert after machining the chip underface observed to be smooth but having lots of void and cracks over it. These voids and cracks are due to the adhesion of coating material with the Al. While machining with multicoated tool insert the sliding marks were clearly visible with regular spacing. In this case, the voids and cracks were more at a lower speed and feed values and it decreases with increasing parameters. The chip morphology showed the formation of the shear band (figure 12); hence it can be inferred that the chips were formed due to shearing action. The shear bands were found to be very dense and overlapped in case of PCD machined chips. In the case of coated tools, the shear band density 
was less and spacing was more compared to uncoated WC and PCD tools.

\section{Conclusion}

The machining of pure $\mathrm{Al}$ was performed using different tools showed the use and effectiveness of WC and PCD tools. The reduction of cutting force and a decrease in surface roughness provided better results for the accurate and finish machining. It also described the formation of BUE and BUL for the machining of $\mathrm{Al}$ and its alloys at different machining conditions. SEM and EDS analysis depicted the adhesion property of $\mathrm{Al}$ with different materials. The following conclusions can be drawn from different experimental studies:

- PCD tools impart lesser forces due to its hardness and chemical inertness towards $\mathrm{Al}$, whereas the coated tools impart higher forces due to the formation of BUE caused due to adhesion of $\mathrm{Al}$.

- The surface finish obtained for the WC tools was better than the rest. Here a roughness value for PCD was bit high due to lesser nose radius. Otherwise, it will be the best tool for machining $\mathrm{Al}$.

- The tool wear of PCD and WC-SPGN showed a better result as compared to coated tools by showing only a few sliding lines. The total removal of the coating layer from the tool tip takes place in TiN and Multicoated tools.

- EDS study conformed the adhesive nature of $\mathrm{Al}$ as it sticks uniformly on the surface of the coated tool and it also states the chemical inactivity of Al towards PCD tool.

- Chip underface and morphology showed the type of chip formation. It also exhibited some micro cracks on the chip underface in case of machining with coated tools which were not desirable.

- For PCD and WC SPUN, at feed $0.045 \mathrm{~mm} / \mathrm{rev}$ and speed of $670 \mathrm{~m} / \mathrm{min}$ are recommended for the machining of aluminium with a comparatively lesser cutting force. Higher speed and low feed rate lead to lesser cutting force.

- But in case of surface roughness point of view, WC SPGN tool will be a better option as its price is less, has a larger nose radius than PCD and it is providing a promising result. For better result, high speed and low feed rate are also recommended.

\section{Acknowledgements}

This work was supported by the Council of Scientific and Industrial Research (CSIR), New Delhi, India (CSIR-22/ (0628)/13/EMR-II). The authors would like to thank all the laboratory staff of VSSUT, Burla for their kind support to carry out this work.

\section{References}

[1] Roy P, Sarangi S K, Ghosh A and Chattopadhyay A K 2009 Machinability study of pure aluminium and Al-12\% Si alloy against uncoated and coated carbide inserts. Int. J. Refract. Met. Hard Mater. 27: 535-544

[2] Zedan Y and Alkahtani S 2013 Influence of the microstructure on the machinability of heat-treated $\mathrm{Al}-10.8 \% \mathrm{Si}$ cast alloys: role of copper-rich intermetallic. J. Mater. Process. Technol. 213: 167-179

[3] Stephenson D A and Agapiou J S 2006 Metal cutting theory and practice, Second Edition. Florida: CRC Press 17-20: 371-416, 459-478, 551-697

[4] Oliaei S N B and Karpat Y 2017 Investigating the influence of friction conditions on finite element simulation of microscale machining with the presence of a built-up edge. Int. J. Adv. Manuf. Technol. 90: 819-829

[5] Fang N, Srinivasa P and Mosquea S 2010 The effect of builtup edge on the cutting vibrations in machining 2024-T351 aluminum alloy. Int. J. Adv. Manuf. Technol. 49: 63-71

[6] Sanchez J M, Rubio E, Alvarez M, Sebastian M A and Marcos M 2005 Microstructural characterisation of material adhered over cutting tool in the dry machining of aerospace aluminium alloys. J. Mater. Process. Technol. 164-165: 911-918

[7] Mário C S, Alisson R M, Wisley F S, Marcos A S B and Emmanuel O E 2016 Machining of aluminum alloys, a review. Int. J. Adv. Manuf. Technol. 86: 3067-3080

[8] Senthil P, Selvaraj T and Sivaprasad K 2013 Influence of turning parameters on the machinability of homogenized $\mathrm{Al}-$ $\mathrm{Cu} / \mathrm{TiB} 2$ in situ metal matrix composites. Int. J. Adv. Manuf. Technol. 67: 1589-1596

[9] Tash M, Samuel F H, Mucciardi Doty H W and Valtierra S 2006 Effect of metallurgical parameters on the machinability of heat-treated 356 and 319 aluminium alloys. J. Mater. Sci. Eng. 434: 207-217

[10] Liang Q, Vohra Y K and Thompson R 2008 High speed continuous and interrupted dry turning of A390 aluminium/ silicon alloy using nanostructured diamond coated WC-6 wt. $\%$ Cobalt tool inserts by MPCVD. Diam. Relat. Mater. 17: 2041-2047

[11] Kalyan C and Samuel G L 2015 Cutting mode analysis in high speed finish turning of $\mathrm{AlMgSi}$ alloy using edge chamfered PCD tools. J. Mater. Process. Technol. 216: 146-159

[12] Gangopadhyay S, Acharya R, Chattopadhyay A K and Sargade V G 2010 Effect of cutting speed and surface chemistry of cutting tools on the formation of BUL or BUE and surface quality of generated surface in dry turning of AA6005 aluminium alloy. Mach. Sci. Technol. 14: 208-223

[13] List G, Nouari M, Géhin D, Gomez S, Manaud J P, Petitcorps Y L and Girot F 2005 Wear behaviour of cemented carbide tools in dry machining of aluminium alloy. Wear 259: 1177-1189

[14] Lim C Y H, Lau P P T and Lin S C 2001 The effect of work material on tool wear. Wear 250: 344-348 
[15] Davim J P 2002 Diamond tool performance in machining metal-matrix composites. J. Mater. Process. Technol. 128: 100-105

[16] Suresh R, Baravarajappa S, Gaitonde V N and Samuel G L 2012 Machinability investigation on hardened steel AISI 4340 steel using coated carbide inserts. Int. J. Refract. Met. Hard Mater. 33: 75-86

[17] Astakhov V P and Xiao X 2008 A methodology for practical cutting force evaluation based on the energy spent in the cutting system. Mach. Sci. Technol. 12: 325-347

[18] Giasin K, Hodzic A and Phadnis V and Ayvar-Soberanis S 2016 Assessment of cutting forces and hole quality in drilling A12024 aluminium alloy: experimental and finite element study. Int. J. Adv. Manuf. Technol. 87: 2041-2061

[19] Basavakumar K G, Mukunda P G and Chakraborty M 2007 Influence of melt treatments and polished CVD diamond coated insert on cutting force and surface integrity in turning of $\mathrm{Al}-7 \mathrm{Si}$ and $\mathrm{Al}-7 \mathrm{Si}-2.5 \mathrm{Cu}$ cast alloys. Bull. Mater. Sci. 30: 427-437

[20] Manna A and Bhattacharaya B 2005 Influence of machining parameters on the machinability of particulate reinforced $\mathrm{Al} /$ SiC-MMC. Int. J. Adv. Manuf. Technol. 25: 850-856

[21] Agustina B D, Bernal C, Camacho A M and Rubio E M 2013 Experimental analysis of the cutting forces obtained in dry turning processes of UNS A97075 aluminium alloys. Procedia Eng. 63: 694-699

[22] Davim J P, Maranhao C, Jackson M J, Cabral G and Grácio J 2008 FEM analysis in high speed machining of aluminium alloy (Al7075-0) using polycrystalline diamond (PCD) and cemented carbide (K10) cutting tools. Int. J. Adv. Manuf. Technol. 39: 1093-1100

[23] Pattnaik S K, Bhoi N K, Padhi S and Sarangi S K 2018 Dry machining of aluminum for proper selection of cutting tool: tool performance and tool wear. Int. J. Adv. Manuf. Technol. 98:55-65

[24] Cakır A, Yagmur S, Kavak N, Kucukturk G and Seker U 2016 The effect of minimum quantity lubrication under different parameters in the turning of AA7075 and AA2024 aluminium alloys. Int. J. Adv. Manuf. Technol. 84: 2515-2521

[25] Feng S and Hattori M 2000 Cost and process information modelling for dry machining. In: International Workshop for Environment Conscious Manufacturing, pp. 1-8

[26] Chattopadhyay A K, Roy P and Sarangi S K 2009 Study of wettability test of pure aluminium against uncoated and coated carbide inserts. Surf. Coat. Technol. 204: 410-417
[27] Kumar R, Minz J K, Sahu D P and Bishoyi S S 2018 Comparative study of measured cutting force and surface roughness for machining of pure aluminium using uncoated and coated carbide inserts. Int. J. Adv. Mech. Eng. 8: 181-190

[28] Tounsi N and Otho A 2000 Dynamic cutting force measuring. Int. J. Mach. Tools Manuf. 40: 1157-1170

[29] Totis G and Sortino M 2011 Development of a modular dynamometer for triaxial cutting force measurement in turning. Int. J. Mach. Tools Manuf. 51: 34-42

[30] Lei X, Shen B and Sun F 2015 Optimization of diamond coated micro drills in aluminium alloy 7075 machining: a case study. Diam. Relat. Mater. 54: 79-90

[31] Su Y, Li Z, Li L, Wang J, Gao H and Wang G 2017 Cutting performance of micro-textured polycrystalline diamond tool in dry cutting. J. Manuf. Process. 27: 1-7

[32] Yuan Z J, Zhou M and Dong S 1996 Effect of diamond tool sharpness on minimum cutting thickness and cutting surface integrity in ultraprecision machining. J. Mater. Process. Technol. 62: 327-330

[33] Pan W, Ding S and Mo J 2014 Thermal characteristics in milling Ti6Al4V with polycrystalline diamond tools. Int. J. Adv. Manuf. Technol. 75: 1077-1087

[34] Gomez-Parra A, Alvarez-Alco M, Silguero J and Batista M, Marcos M 2013 Analysis of the evolution of the Built-Up Edge and Built-Up Layer formation mechanisms in the dry turning of aeronautical aluminum alloys. Wear 302: 1209-1218

[35] Chattopadhyay A B, FNA (E) 2011 Machining and Machine Tools. Wiley - India Publication

[36] Chattopadhyay A K, Roy P, Ghosh A and Sarangi S K 2009 Wettability and machinability study of pure aluminium towards uncoated and coated carbide cutting tool inserts. Surf. Coat. Technol. 203: 941-951

[37] Chakravarthy G V, Chandran M, Bhattacharya S S, Rao M S R and Kamaraj M 2012 A comparative study on wear behaviour of TiN and diamond coated WC-Co substrates against hypereutectic Al-Si alloys. Appl. Surf. Sci. 261: $520-527$

[38] Xiao X, Lev L C and Lukitsch M J 2009 Material transfer during machining of aluminum alloys with polycrystalline diamond cutting tools. J. Mater. Process. Technol. 209: 5760-5765

[39] Wang B and Liu Z 2016 Investigations on deformation and fracture behaviour of workpiece material during high speed machining of 7050-T7451 aluminum alloy. CIRP J. Manuf. Sci. Technol. 14: 43-54 